\title{
EDITORIAL
}

Esta obra está bajo licencia Creative Commons

Attribution-NonCommercial-ShareAlike $\quad 4.0$

International (CC BY-NC-SA 4.0)

La crítica racional debe ser siempre específica: debe ofrecer fundamentos específicos de por qué parecen ser falsas afirmaciones especificas, hipótesis específcas o argumentos específicos no válidos. Debe ser guiada por la idea de acercarse en lo posible a la verdad objetiva. Debe, en este sentido, ser impersonal.

Karl R. Popper

\section{EL CIENTÍFICO SOCIAL Y LA NECESIDAD DEL ACCESO ABIERTO PARA DAR A CONOCER SUS HALLAZGOS}

El espíritu del ser humano, por ser un observador de la realidad social y por sus habilidades que le permiten identificar, analizar, clasificar e interpretar la información que percibe a partir de su interacción con esa realidad; debe poseer una actitud, producto del pensamiento crítico, metódico y ordenado, que permita al científico social desarrollar su investigación en beneficio de la solución de problemas y, con ello, contribuir a una sociedad más justa y pacífica. Así, el investigador de las ciencias sociales hace un gran esfuerzo por desarrollar de manera constante sus habilidades, en particular el "pensamiento crítico" como una forma que coadyuva a su crecimiento profesional y durante ese proceso acumula conocimiento, información y experiencias, además de que esa habilidad le permite impulsar hallazgos más analíticos y profundos en los resultados de su investigación:

Esta capacidad de pensar críticamente hace a los investigadores más curiosos e interesados en sus propósitos de búsqueda profesional, y definitivamente hace que la producción y resultados de investigaciones sean cada vez más precisos y direccionados a resolver problemáticas de índole e incidencia mundial (Mackay, et. al., 2018).

También, el quehacer de la investigación social debe influir de manera positiva en la solución de problemas sociales y la crítica racional debe encaminar al investigador y acercarlo en mayor medida a la verdad objetiva. El científico social, como ente generador de ciencia, tiene la obligación metodológica de romper y ampliar paradigmas que permitan mantener distancia entre la ciencia y las nociones comunes, es decir, "una crítica lógica y lexicológica del lenguaje común, con el objeto de elaborar y reelaborar controladamente las nociones científicas” (Batthyány y Cabrera, 2011, p. 16), para con ello lograr una mayor objetividad tanto en el producto de la investigación como en el proceso, sean métodos o técnicas de investigación. Es en este sentido que, "mediante procedimientos metódicos con la pretensión de validez, utilizando la reflexión, los razonamientos lógicos y respondiendo a la búsqueda intencionada, para lo cual se delimitan los objetos y se prevén los modelos de investigación” (Batthyány y Cabrera, 2011, p. 12), podemos considerar que los resultados de la investigación realizada se obtendrán bajo el mayor rigor científico y sus funciones permitirán describir, comprender y explicar fenómenos de la realidad social. De esta manera, sabemos que tal esfuerzo por mejorar las condiciones de vida de la humanidad a través de los hallazgos científicos es en realidad una relación de seres humanos para seres humanos; en consecuencia, lo más lógico es que los resultados de estas investigaciones sean de acceso abierto. 
Como sabemos, el acceso a la ciencia se ha encontrado limitado por aspectos de carácter económico, legal o técnico que monopolizan su uso y evitan puntos de equilibro entre el desarrollo científico y la solución de problemas que impactan en la sociedad; es por ello que, a contrario sensu y de acuerdo con la Iniciativa de Budapest para el Acceso Abierto (2002), se define al "acceso abierto" (open access) como "disponibilidad gratuita en internet pública, para que cualquier usuario pueda leer, descargar, copiar, distribuir, imprimir, con la posibilidad de buscar o enlazar los textos de estos artículos (...) utilizarlos para cualquier propósito legal, sin barrera financieras, legales o técnicas", y para lograr un acceso abierto a la literatura académica que se publica de manera periódica es necesario, entre otros aspectos, incorporar medios de publicaciones periódicas que ofrezcan a los autores una forma de visibilidad, legibilidad e impacto, además de que se comprometan con la característica de "abierto" para su acceso, garanticen la gratuidad sin restricciones y aprovechen los medios electrónicos de que disponemos actualmente; con esto, una mayor diversidad de autores y lectores podrán encontrar, tener acceso y utilizar información relevante y de interés. Así, la revista Ius Comitiãlis, editada por la Universidad Autónoma del Estado de México (UAEMéx) a través de su Facultad de Derecho, se erige en un medio de difusión y divulgación científica que brinda la posibilidad a los autores de publicar los principales hallazgos de sus investigaciones, esto -desde luego-bajo un proceso de revisión por pares ciegos (double blind peer review), necesario para garantizar tanto el rigor científico de lo que se publica como el compromiso que, al ser una institución académica, tenemos con la comunidad científica.

Por lo anterior, ponemos a consideración de nuestros lectores el fascículo número 7 del volumen 4, que cuenta con la participación de excelentes académicos, quienes nos han elegido como el medio que someta el producto de su investigación y sus principales hallazgos a cada una de las etapas del proceso editorial. Este fascículo cuenta con doce artículos que exponen la relevancia de los fenómenos propios de la cobertura temática: Derecho constitucional, Derecho Electoral, Teoría Constitucional y Teoría de la Democracia. Cabe mencionar que en Ius Comitiãlis nuestro compromiso es constante con el acceso libre (open access) y con la gratuidad de los artículos, por ello, con el apoyo del Consejo Científico y del Comité Editorial, los integrantes del Equipo Editorial hemos sumado esfuerzos para garantizar la calidad de lo que se publica y para mantener y ampliar nuestra cobertura. Finalmente, la recepción de trabajos de aquellos interesados en postular los resultados de su investigación sujetos a la cobertura temática se encuentra abierta de forma permanente para su posible publicación. 


\section{Referencias}

1. Batthyány, Karina y Cabrera, Mariana (coords.) (2011) La articulación del campo epistemológico y el metodológico como objetivo central de un proyecto de investigación, Comisión Sectorial de Enseñanza Universidad de la República, Montevideo.

2. BOAI (2002) Iniciativa de Budapest para el Acceso Abierto, Disponible en: http://www. soros.org/openaccess/translations/spanish-translation Fecha de consulta 28 de mayo del 2021.

3. Mackay Castro, R., et. al. (2018). “El pensamiento crítico aplicado a la investigación”. Universidad y Sociedad, 10(1), pp. 336-342. Recuperado de http://rus.ucf.edu.cu/index. $\mathrm{php} / \mathrm{rus}$ Fecha de consulta 28 de mayo del 2021.

4. Popper, Karl (1981) "Tolerancia y responsabilidad intelectual”, conferencia pronunciada el 26 de mayo de 1981, Universidad de Tubinga, Alemania. Recuperado de http://www.revistas.unam.mx/index.php/rep/article/view/37249 Fecha de consulta 28 de mayo del 2021. 